\title{
Androgens as adjuvant treatment in postmenopausal female patients with rheumatoid arthritis
}

\author{
A Booij, C M Biewenga-Booij, O Huber-Bruning, C Cornelis, J W G Jacobs, J W J Bijlsma
}

\begin{abstract}
Objective-To examine the possible beneficial effect of androgens in postmenopausal women with active rheumatoid arthritis.

Methods-107 women participated in a double blind placebo controlled trial to evaluate the effect of $50 \mathrm{mg}$ testosterone propionate intramuscularly every two weeks for one year.

Results-An improvement in ESR, Dutch health assessment questionnaire, and pain was noted. In addition, $21 \%$ of patients treated with testosterone fulfilled the ACR improvement criteria after one year, versus only $4 \%$ of the placebo group. The treatment was well tolerated.

Conclusions-Testosterone may improve the general wellbeing of postmenopausal women with active rheumatoid arthritis.
\end{abstract}

(Ann Rheum Dis 1996;55:811-815)

Among the factors which predispose to and modulate rheumatoid arthritis, sex hormones are important: androgens act as natural immunosuppressants and oestrogens perhaps as enhancers of the immune response. ${ }^{1}$ Low androgen concentrations are present before and after the onset of rheumatoid arthritis in both male and female patients. ${ }^{2}$ In particular, serum levels of the adrenal androgen, dehydroepiandrosterone (DHEA) sulphate, are found to be consistently low, while an inverse correlation with disease severity has been shown. ${ }^{3}{ }^{4}$ Some in vitro studies support the view that androgens may be regarded as natural immune suppressors: they inhibit the production of cytokines by activated murine $T$ lymphocytes ${ }^{5}$ and they increase suppressor cell activity in both thymocytes and lymphocytes. Furthermore, human macrophages carry functional cytoplasmic and nuclear androgen receptors ${ }^{6}$; these macrophages are abundant in synovial tissue from patients with rheumatoid arthritis. Androgen receptors have also been observed on cultured human fetal chondrocytes. In animal models of rheumatoid arthritis, testosterone was found to reduce inflammation and inhibit the occurrence of erosions.

There are only limited data on the possible clinical effects of androgen treatment for patients with active rheumatoid arthritis. What was probably the first study was published in $1950 .^{8}$ Testosterone propionate was given to a limited number of patients with active rheuma- toid arthritis and it was concluded that significant improvement, or even remission, might follow treatment of early rheumatoid arthritis. However, side effects limited the feasibility of this approach. In The Netherlands the beneficial effect of testosterone propionate in a female rheumatoid arthritis patient was observed by a general practitioner (Booij A Sr, unpublished clinical observation, 1960. In a more recent study, treatment of postmenopausal rheumatoid arthritis patients with 19nortestosterone for six months was found to improve chronic anaemia but not indices of disease activity or functional capacity. ${ }^{9}$ In a study of male patients the effect of (oral) testosterone undecanoate on rheumatoid arthritis disease activity was more evident ${ }^{10}$ : erythrocyte sedimentation rate (ESR) and IgM rheumatoid factor levels decreased, as did the number of tender joints and the daily intake of non-steroidal anti-inflammatory drugs (NSAID).

On the grounds of these in vitro and in vivo findings we performed a double blind, placebo controlled study of postmenopausal women with rheumatoid arthritis to determine the effects of testosterone on disease activity.

\section{Methods}

PATIENTS

One hundred and seven postmenopausal women with active rheumatoid arthritis, satisfying the American College of Rheumatology 1987 criteria, ${ }^{11}$ entered the study. Inclusion criteria were active rheumatoid arthritis characterised by at least three of the following: six or more tender joints; three or more swollen joints; ESR > $28 \mathrm{~mm}$ in the first hour; $\mathrm{C}$ reactive protein $>30 \mathrm{mg}$ litre $^{-1}$; morning stiffness exceeding 30 minutes.

Exclusion criteria were: renal dysfunction, defined as serum creatinine $\geq 120 \mu \mathrm{mol}$ litre $^{-1}$; hypertension, defined as a diastolic blood pressure of $95 \mathrm{~mm} \mathrm{Hg}$ or more and/or a systolic blood pressure of $170 \mathrm{~mm} \mathrm{Hg}$ or more; concomitant angina pectoris or a myocardial infarction in the past; suspicion of breast carcinoma (in case of doubt, mammography was performed); hyperlipidaemia or raised liver enzymes, defined as more than $1 \mathrm{SD}$ above the upper limit of normal.

Patients came from all over The Netherlands and were first seen in Dr A Booij's general practice. If they were willing to participate and satisfied the entrance criteria they were referred to the University Hospital Utrecht for this study. The study protocol was approved by the ethics committee of this hospital and all 
patients gave their informed consent. All measurements were performed by the same observer (OH-B).

Patients were randomly allocated to one of two groups: one group (testosterone) received an intramuscular injection of $50 \mathrm{mg}$ testosterone propionate and $2.5 \mathrm{mg}$ progesterone every other week; the other group (placebo) received placebo injections consisting of the vehicle. The dosage of $50 \mathrm{mg}$ testosterone was based on limited clinical experience in postmenopausal women with rheumatoid arthritis and on larger experience in postmenopausal women with osteoporosis. The small dosage of progesterone was added to the original regimen (1960) of $\mathrm{Dr}$ Booij Sr to reduce the androgenic influence of testosterone on the female sex organs. This dosage is nowadays considered too low to have any clinically relevant effect. Intramuscular treatment was continued for 12 months. Patients were allowed to continue their NSAID and disease modifying antirheumatic drug medication, on the condition that the dosage was stable three months before and during the whole study period. No intra-articular injections were allowed in the month before clinical assessments. Some patients took glucocorticosteroids; in all cases the dosage was below $7.5 \mathrm{mg}$ per day and was stable three months before and during the whole study period. Thus androgen treatment could be considered as adjuvant treatment.

Patients were seen at the rheumatology outpatient department for baseline evaluation and after six and 12 months. The allocated medication was supplied by the pharmacy of the hospital; patients took this medication home, where they were injected every other week by their general practitioner or a nurse.

At baseline, the following characteristics were recorded: age, mean disease duration; use of NSAID and disease modifying antirheumatic drugs; other medication; presence or absence of erosions on $x$ rays, and rheumatoid factor status. In addition haemoglobin concentration, serum creatinine, and liver function tests were monitored.

The following outcome measures were assessed, based on the WHO/ILAR core set of endpoints for rheumatoid arthritis clinical trials. ${ }^{12}$ In line with the decisions of EULAR and ACR subcommittees, an unweighted 28 joint count, which assesses tenderness and swelling separately, was used ${ }^{13} ;$ ESR, measured by the Westergren method; functional disability with a validated Dutch version of the Stanford health assessment questionnaire (HAQ), range $0-3^{14}$; pain and general wellbeing with the validated Dutch IRGL (influence of rheumatic diseases on general health and lifestyle ${ }^{15}$ ), partially based on the AIMS ${ }^{16}$ range for pain 6-25, range for general wellbeing 0-24.

For determination of individual clinically relevant improvement, the preliminary ACR criteria were used. ${ }^{17}$ Since this study was designed before publication of these criteria we had to adopt slight modifications: for variable pain (VAS), the pain scale of the IRGL was used; for global assessments by the patient and physician, the opinion of the patient/physician on improvement after 12 months of treatment was applied, whereby "much" or "moderate" improvement was considered sufficient to satisfy the criteria $(20 \%$ or more improvement).

\section{STATISTICAL METHODS}

For between group comparisons of means, two-sample $t$ tests and Wilcoxon rank sum tests were used where appropriate. Since there were statistically significant differences at baseline between the two groups in two variables, change scores were computed: differences in baseline and post-treatment scores between the testosterone and placebo groups were compared using two-sample $t$ tests and Wilcoxon rank sum tests where appropriate. For comparison of proportions, Fisher's exact tests were applied.

Intention to treat was applied throughout the analysis of this study for withdrawals, including the last assessment. Missing data were considered as treatment failures. All tests were two sided; $P$ values $<0.05$ were considered to be statistically significant. Statistical analyses were performed with the Number Cruncher Statistical System software package version 6.0

\section{Results}

The demographic and baseline disease characteristics of the patients are shown in table 1:57 patients underwent active treatment (testosterone) and 50 patients received the placebo. There was no difference in demographic characteristics; however, it appeared that there was a statistically significant difference in pain and the disability score. Both suggested less disease activity in the placebo group. In table 2 the results of the intent-to-treat analysis of the efficacy of treatment are given. No significant differences between the two groups were noted after one year of treatment. Recently a definition of improvement in rheumatoid arthritis was formulated that corresponds closely to the prevailing impression of patient improvement among rheumatologists and discriminates between patients on active drug treatment and those receiving the placebo. ${ }^{17}$ According to this definition, at 12 months 12 patients of the testosterone group $(21 \%)$ and only two in the placebo group (4\%) fulfilled these criteria $(P<0.01)$. Since there was a significant difference in two indices of disease activity between the two groups at the start of the study, change scores were calculated (table 3 ). There was significantly more improvement after one year in pain score ( $4 v 1 ; 95 \%$ confidence intervals (CI) -1 to $7 v-3$ to 4 ), ESR (9 $v 0 ; 95 \%$ CI 4 to $14 v-3$ to 3 ), and disability score $(0.24 v-0.24 ; 95 \% \mathrm{CI}-0.01$ to $0.46 v$ -0.49 to 0.03 ) in the testosterone group.

Monitoring of safety indices at one year showed a significant increase in haemoglobin concentration in the testosterone group (0.3 mmol litre $\left.{ }^{-1}\right) v$ no change in the placebo group. No changes were found for the serum levels of 
Table 1 Baseline characteristics of the patients

\begin{tabular}{|c|c|c|c|c|}
\hline & Total & Testosterone & Placebo & $\begin{array}{l}p \text { Value test } \\
\text { vs placebo }\end{array}$ \\
\hline $\mathbf{n}$ & 107 & 57 & 50 & \\
\hline Age (years) ${ }^{\star}$ & $62(8)$ & $62(8)$ & $62(7)$ & \\
\hline Disease duration $(y)^{\star}$ & $14(12)$ & $14(13)$ & $15(12)$ & \\
\hline NSAID users (\%) & 91 & 92 & 90 & \\
\hline DMARD users (\%) & 62 & 67 & 55 & \\
\hline Prednisone users (\%) & 21 & 19 & 23 & \\
\hline Erosions on $\mathrm{X}$-rays (\%) & 82 & 82 & 81 & \\
\hline Rheumatoid factor (\%) & 86 & 85 & 87 & \\
\hline 28 Swollen joint count ${ }^{\star}$ & $8.6(4.5)$ & $8.0(4.5)$ & $9.2(4.5)$ & \\
\hline 28 Tender joint count ${ }^{\star}$ & $10.7(5.7)$ & $11.3(6.0)$ & $10.0(5.2)$ & \\
\hline $\mathrm{ESR} \mathrm{mm} / \mathrm{lh}^{\star}$ & $49(25)$ & $52(26)$ & $46(23)$ & \\
\hline HAQ-disability * & $1.54(0.89)$ & $1.77(0.86)$ & $1.31(0.91)$ & 0.007 \\
\hline Pain $(\text { IRGL) })^{\star}$ & $19(4)$ & $20(4)$ & $18(4)$ & 0.006 \\
\hline
\end{tabular}

* Mean (standard deviation)

Table 2 Intent-to-treat analysis: absolute values (means and standard deviations) of differences between testosterone and placebo groups

\begin{tabular}{|c|c|c|c|}
\hline & $T=0$ months & $T=6$ months & $T=12$ months \\
\hline \multicolumn{4}{|c|}{28 Swollen joint count: } \\
\hline Testosterone & $8.0(4.5)$ & $7.1(5.1)$ & $7.2(5.6)$ \\
\hline Placebo & $9.2(4.5)$ & $\begin{array}{l}8.9(4.8) \\
p=0.038\end{array}$ & $8.9(5.5)$ \\
\hline \multicolumn{4}{|c|}{28 Tender joint count: } \\
\hline Testosterone & $11.3(6.0)$ & $10.2(6.8)$ & $9.9(6.7)$ \\
\hline Placebo & $10.0(5.2)$ & $8.7(5.7)$ & $9.3(6.0)$ \\
\hline \multicolumn{4}{|l|}{ ESR mm/lh: } \\
\hline Testosterone & $52(26)$ & $42(22)$ & $42(22)$ \\
\hline Placebo & 46 (23) & $44(21)$ & $46(25)$ \\
\hline \multicolumn{4}{|l|}{ Dutch HAQ: } \\
\hline Testosterone & $1.77(0.86)$ & $1.66(0.75)$ & $1.54(0.90)$ \\
\hline Placebo & $1.31(0.91)$ & $1.30(0.94)$ & $1.55(0.79)$ \\
\hline & $P=0.007$ & & \\
\hline \multicolumn{4}{|l|}{ Pain-scale: } \\
\hline Testosterone & $20(4)$ & $17(5)$ & $17(5)$ \\
\hline Placebo & $\begin{array}{l}18(4) \\
P=0.006\end{array}$ & $18(5)$ & $18(5)$ \\
\hline \multicolumn{4}{|c|}{$\begin{array}{l}\text { Number fulfilling preliminary ACR } \\
\text { improvement criteria: }\end{array}$} \\
\hline Testosterone & - & 10 & 12 \\
\hline Placebo & - & 4 & $\begin{array}{l}2 \\
P=0.008\end{array}$ \\
\hline
\end{tabular}

$\mathrm{P}$ values denote significant differences between the testosterone and placebo groups at that moment in time.

Table 3 Intent-to treat analysis: change scores (means and standard deviations) of differences between testosterone and placebo groups

\begin{tabular}{llll}
\hline & $\Delta 0-6 m$ & $\Delta 6-12 m$ & $\Delta 0-12 m$ \\
\hline $\begin{array}{l}\text { 28 Swollen joint count: } \\
\text { Testosterone }\end{array}$ & $0.9(3.9)$ & $-0.1(30)$ & $0.8(4.7)$ \\
Placebo & $0.4(4.0)$ & $-0.1(3.3)$ & $0.3(5.2)$ \\
28 Tender joint count: & & & \\
Testosterone & $1.1(5.2)$ & $0.3(3.0)$ & $1.4(5.9)$ \\
Placebo & $1.3(4.9)$ & $-0.6(4.3)$ & $0.6(4.9)$ \\
ESR mm/1h: & & & \\
Testosterone & $10(17)$ & $0(14)$ & $9(19)$ \\
Placebo & $1(10)$ & $-1(10)$ & $0(12)$ \\
Dutch HAQ: & $\mathrm{P}=0.006$ & & $\mathrm{p}=0.01$ \\
Testosterone & $0.11(0.82)$ & $0.12(0.76)$ & $0.24(0.84)$ \\
Placebo & $0.01(0.88)$ & $-0.25(0.59)$ & $-0.24(0.86)$ \\
Pain scale: & & $\mathrm{P}=0.005$ & $\mathrm{P}=0.004$ \\
Testosterone & $3(5)$ & $0(4)$ & $4(6)$ \\
Placebo & $1(4)$ & $0(5)$ & $1(4)$ \\
& & & $\mathrm{P}=0.002$ \\
\hline
\end{tabular}
$\mathrm{P}$ values denote significant differences between the testosterone and placebo groups at that
moment in time. Direction of differences: + (not indicated) is improvement, - is worsening.

creatinine, alkaline phosphate, or $\gamma$-glutamyl transferase (data not shown).

Patients were asked whether or not they would like to continue their allocated medication after completing one year of treatment: $67 \%$ of the testosterone group wanted to continue treatment versus only $37 \%$
Table $4 a$ Drop-outs (number of patients)

\begin{tabular}{|c|c|c|c|}
\hline & $0-6 m$ & 6-12 m & Total \\
\hline \multicolumn{4}{|l|}{ Testosterone treatment } \\
\hline Side effects & 2 & - & 2 \\
\hline Inefficacy ${ }^{\star}$ & 11 & 5 & 16 \\
\hline Protocol violation & 1 & 2 & 3 \\
\hline Total & 14 & 7 & 21 \\
\hline \multicolumn{4}{|l|}{ Placebo treatment } \\
\hline Side effects & 2 & 2 & 4 \\
\hline Inefficacy ${ }^{\star}$ & 7 & 5 & 12 \\
\hline Protocol violation & 2 & - & 2 \\
\hline Total & 11 & 7 & 18 \\
\hline Total & 25 & 14 & 39 \\
\hline
\end{tabular}

^ Inefficacy: every change in DMARD was considered as lack of efficacy.

Table $4 b$ Side effects: (number of patients) *

\begin{tabular}{lll}
\hline & Testosterone & Placebo \\
\hline Hypertrichosis & 8 & 2 \\
Hoarse voice & 1 & 2 \\
Painful breasts & 1 & 1 (heart attack) \\
Sudden death & & 1 \\
Thrombosis central retinal vein & & \\
\hline
\end{tabular}

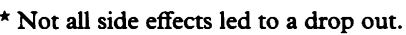

of the placebo group; this is a statistically significant difference.

As an additional index, the number of joints injected with corticosteroids was recorded. Ten patients of the testosterone group received a total of 14 injections; in the placebo group nine patients received a total of 18 injections: the difference is not significant. No significant change in the use of NSAID was found between the two groups during treatment.

Only 68 patients completed one year of treatment: 36 of 57 patients in the treatment group and 32 of 50 patients in the placebo group. No difference was found in demographic or disease characteristics between the total group $(n=107)$, those who completed this study $(n=68)$, and those who dropped out ( $n=39$; data not shown).

The most important reasons for dropping out were (table 4): protocol violation $(n=5$; testosterone 3; placebo 2 ), side effects ( $n=6$; testosterone 2; placebo 4), and lack of efficacy ( $n=28$; testosterone 16 ; placebo $12 ; 18$ in the first period). Every change in disease modifying antirheumatic drug dose was considered a lack of efficacy.

Protocol violations occurred when the patient's own general practitioner or local rheumatologist objected to this adjuvant therapy (three patients), one patient moved to southern Europe, and one patient went into remission. Six patients stopped treatment because of side effects: two suffered palpitations and general malaise (1 testosterone and 1 placebo), one reported loss of hair (placebo), and one had gastrointestinal symptoms (testosterone). One woman died of a myocardial infarct (placebo) and one had a thrombosis of the central retinal vein (placebo).

The most common side effects are listed in table 4. As expected the following side effects of testosterone were seen: hypertrichosis, a hoarse voice, and remarkably in one case painful breasts. Eight of 36 patients who completed 
12 months of androgen treatment suffered hypertrichosis; however, two placebo treated patients also reported hypertrichosis. A hoarse voice was evident in one patient treated with androgens and two patients receiving the placebo. Before patients entered the study the possible masculinising side effects of treatment were described; none of the patients considered them a serious problem and none of the patients stopped treatment for this reason.

\section{Discussion}

The clinical effect of androgens as adjuvant treatment for postmenopausal women with rheumatoid arthritis was evaluated on the basis of previous in vitro and in vivo findings. In general treatment was well tolerated; an improvement in pain score, ESR, and disability score was found, and $21 \%$ of patients showed clinically relevant improvement. No serious side effects were noted. However, there may be some concern for possible undesirable androgenic effects during continued use of androgens in postmenopausal women, especially on the cardiovascular system.

Although all patients had active disease at the start of the study, it was found that, notwithstanding randomisation, the group of 57 patients treated with testosterone had more active disease (pain and disability score) at the start of the study than the group of 50 patients receiving the placebo. For this reason change scores were also calculated for both groups. During the treatment period, disease activity decreased in patients treated with testosterone, while it remained the same in patients receiving the placebo. There was a significant difference in swollen joint count at six months but not at 12 months between the two groups; ESR and HAQ improved more in the testosterone group. In addition, $21 \%$ of patients experienced clinically relevant improvement. These findings suggest that apart from the known positive anabolic effect of this therapeutic agent, there might also be a slight disease modifying effect.

A problem of this study is the relatively large numbers of efficacy failures and drop outs in both groups. Though there is good in vitro evidence for a possible beneficial role of androgens in immunomodulation of rheumatoid arthritis, this approach is considered by many to be alternative medicine. ${ }^{18}$ It was therefore not always possible to prevent changes in disease modifying antirheumatic drug dosage by general physicians or other doctors. Since it was impossible to decide whether such dose changes were due to lack of efficacy or for another reason, every change in treatment with these agents (including a reduced dose and even in some cases discontinuation) was considered lack of efficacy. Thus a very conservative evaluation was made.

The mild beneficial effects of androgens in postmenopausal women with rheumatoid arthritis in the present study are comparable with earlier findings for male rheumatoid arthritis patients. Cutolo et al ${ }^{10}$ gave oral testo- sterone undecanoate $(120 \mathrm{mg}$ daily for six months) and found a reduction in joint score and the intake of NSAID; in addition he noted a decrease in IgM rheumatoid factor and ESR. In that small sample of seven patients, two experienced a flare of rheumatoid arthritis after cessation of testosterone.

It is relevant to note that adjuvant treatment with oestrogens of postmenopausal women also led to an improvement in general wellbeing (and bone mass) but had no effect on disease activity. ${ }^{19}{ }^{20}$ Adjuvant treatment with androgens might cause more immunomodulation in rheumatoid arthritis than adjuvant treatment with oestrogens. Treatment with testosterone of postmenopausal women with rheumatoid arthritis is likely to improve bone mass $^{21}$; however, this was not assessed in this study.

In conclusion, we suggest that androgens can be considered as adjuvant therapy for postmenopausal women with rheumatoid arthritis: theoretically the effect is anabolic and perhaps also slightly disease modifying. Since more potent disease modifying agents are available, the main indication for androgen treatment will probably be improvement of the catabolic state prevalent among so many of the elderly patients with active rheumatoid arthritis.

We would like to thank Mrs A J M Jacobs-van Bree for data management and Mrs G de Kruijf for secretarial assistance. This study was supported by a grant from the Booij Senior Fund.

1 Cutolo M, Seriolo B, Sulli A, Accardo S. Androgens in rheumatoid arthritis. In: Bijlsma JWJ, Linden $S$ van der, Barnes CG, eds. Rheumatology highlights 1995. Rheumatol Eur 1995;24(S-2):211-4.

2 Masi AT, Feigenbaum SL, Chatterton RT. Hormonal and pregnancy relationships to rheumatoid arthritis: Convergent effects with immunological and microvascular systems. Semin Arthritis Rheum 1995;25:1-27.

3 Wilder RL. Neuroendocrine-immune system interactions and autoimmunity. Annu Rev Immunol 1995;13:307-38.

4 Hall GM, Perry LA, Spector TD. Depressed levels of dehydroepiandrosterone sulphate in postmenopausal women with rheumatoid arthritis, but no relation with axial bone density. Ann Rheum Dis 1993;52:211-4.

5 Araneo BA, Dowel T, Dieguel M, Daynes RA. Dihydrotestosterone exerts a depressive influence on the production of interleukin-4, IL -5 and tIFN, but not IL -2 by activated murine cells. Blood 1991;78:688-99.

6 Cutolo M, Accardo S, Villagio B, Clerico P, Indiveri F, Carruba $\mathrm{G}$, et al. Evidence for the presence of androgen receptors in $\mathrm{G}$, et al. Evidence for the presence of androgen receptors in the synovial tissue of theumatoid arthritis patie

7 Da Silva JAP, Larbre JP, Seed M, Cutolo M, Villagio B, Scott DL, et al. Sex differences in inflammation induced cartilage damage in rodents. $\mathcal{F}$ Rheumatol 1994;21:330-7.

8 Margolis HM, Caplan PS. The effect of some steroids in rheumatoid arthritis. Ann Intern Med 1951;34:61-71.

9 Bird HA, Burkinshaw L, Pearson D, Atkinson PJ, Leathman $\mathrm{PA}$, Hill J, et al. A controlled trial of nandrolone decanoate in the treatment of rheumatoid arthritis in postmenopauin the treatment of rheumatoid arthritis in post

10 Cutolo M, Balleari E, Giusti M, Intra E, Accardo S. Androgen replacement therapy in male patients with rheumatoid arthritis. Arthritis Rheum 1991;34:1-5.

11 Arnett FC, Edworthy SM, Block DA, McShane DJ, Frics JF, Cooper NS, et al. The American Association 1987 revised criteria for the classification of rheumatoid arthritis. Arthritis Rheum 1988;31:315-24.

12 Boers $M$, Tugwell $P$. Outcome measures in rheumatoid arthritis clinical trials. $\mathcal{F}$ Rheumatol 1993;20:525-91.

13 Prevoo ML, Van't Hof MA, Kuper HH, Van leeuwen MA, Van de Putte LBA, Van Riel PLCM. Modified disease activity scores that include twenty-eight-joint counts: development and validation in a prospective longitudinal development and validation in a prospective longitudinal study of patients

14 Bijlsma JWJ, Oude Heuvel CHB, Zaalberg A. Development and validation of the Dutch questionnaire Capacities of Daily Life (VDF) for patients with rheumatoid arthritis. $f$ Rehabil Sci 1990;3:71-4.

15 Huiskes CJAE, Kraaimaat FW, Bijlsma JWJ. Development of a self-report questionnaire to assess the impact of 
theumatic diseases on health and lifestyle. $\mathcal{F}$ Rehabil $S c i$ 1990;3:75-80.

16 Meenan RF, Gertman PM, Mason JM. Measuring health status in arthritis: the Arthritis Impact Measurement Scale. Arthritis Rheum 1980;23:146-53.

17 Felson DT, Anderson JJ, Boers M, Bombardier C, Furst D, Goldsmith C, et al. American College of Rheumatology preliminary definition of improvement in rheumatoid preliminary definition of improvement
arthritis. Arthritis Rheum 1995;38:727-35.

18 Panush RM. Nontraditional remedies. In: Schumacher RH Klippel JH, Koopman WJ, eds. Primer on the rheumatic diseases 1993;10:323-7.
19 Brink HR van den, Lems WF, Everdingen AA van, Bijlsma JWJ. Adjuvant oestrogen treatment increases bone mineral density in postmenopausal women with rheumatoid arthritis. Ann Rheum Dis 1993;52:302-5.

20 Bijlsma JWJ, Brink HR van den. Estrogens and rheumatoid arthritis. Am $\mathcal{F}$ Reprod Immunol 1992;28:231-4.

21 Lyritis GP, Androulakis C, Magiasis B, Charalambaki Z Tsakalakos N. Effect of nandrolone decanoate and $1 \alpha$ hydroxy calciferol on patients with vertebral osteoporotic collapse. A double-blind clinical trial. Bone Miner Res 1994;27:209-17. 